Plant Tissue Cult. \& Biotech. 30(2): 209-218, 2020 (December)

(CBangladesh Assoc. for Plant Tissue Culture \& Biotechnology

$\overline{\text { PTC\&B }}$

\title{
Chemical Mutagens Affecting in vitro Behavior of Gardenia jasminoides
}

\author{
Eman Tawfik* and Mohamed Fathy ${ }^{1}$ \\ Department of Botany and Microbiology, Faculty of Science, Helwan University, Egypt
}

Key words: Chemical mutagens, Gardenia jasminoides, Guanidine hydrochloride, Photosynthetic pigmentations

\begin{abstract}
The chemical mutagens, namely sodium azide and guanidine hydrochloride (30, 40 and $50 \mathrm{mM}$ ) for each were applied for the in vitro culture of Gardenia jasminoides Ellis. Eight morphological traits were evaluated to calculate the result of different concentrations of mutagens compared to control. In sodium azide, all morphological traits decreased compared to control, except the number of branches and leaves and leaf length, which increases compared to control. Unlike guanidine hydrochloride, all the morphological traits are enhanced in mutants rather than control. The polymorphism percentage resulted from genetic variation varied $(57.71 \%$ in the case of sodium azide and $67.59 \%$ in guanidine hydrochloride). Hence, guanidine hydrochloride is a more powerful mutagen and causes more genetic variations and instability than sodium azide, as was reflected in morphological parameters (i.e., fresh weight, shoot length, root length, number of lateral roots, number of leaves, numbers of branches, leaf length, and leaf width) and physiological traits (i.e., chlorophyll pigmentation and carotenoids).
\end{abstract}

\section{Introduction}

Gardenia jasminoides (Ellis) is an ornamental plant with fragrant white flowers and is commonly known as gardenia or cape jasmine. It is an evergreen plant and belongs to the family Rubiaceae. It is also known as palm lily and cappage palm. It grows in warmtemperate, humid and tropical regions. It is usually cultivated indoors or outdoors in gardens. It prefers bright indirect sunlight or partial shade rather than direct sunlight. It is preferred to be cultured in quite acidic medium or soil (4.5 - 5.5) to obtain all nutrients. It is also considered a medicinal plant as it has numerous biological activities in both in

*Author for correspondence: <emantawfik@science.helwan.edu.eg>. 1Department of Horticulture, Faculty of Agriculture, Ain Shams University, Egypt.

DOI: https://doi.org/10.3329/ptcb.v30i2.50691 
vitro and in vivo conditions. It has antidiabetic, antioxidant, antidepression, antiinflammatory properties. It is also used to treat wounds, fever, hepatitis, influenza (Soliman et al. 2013 and Xiao et al. 2017 and Kesavan et al. 2018).

An induced chemical mutation is a method to make genetic variation leading to new varieties with better characteristics. Induced mutations are also used to provide a novel source of resistance to biotic and abiotic stress factors whereby a new resistant variety can be developed (El-Mokadem and Mostafa 2014, Suprasanna et al. 2015).

Sodium azide $\left(\mathrm{NaN}_{3}\right)$ is one of the most robust chemical mutagens used in plants. Its application on the plant is easy and inexpensive and creates mutations to improve their traits. The efficiency of the mutant relies on several circumstances, like the concentration of azide and the treatment duration. It creates point mutation and damages the chromosomes and produces tolerance in the plants for numerous adverse conditions (ElMokadem and Mostafa 2014).

Guanidine hydrochlorides are a group of chemical mutagens capable of causing alkylation for nitrogenous bases of DNA structure. The guanidine hydrochlorides act as energy transfer inhibitors. There are three groups of guanidine hydrochlorides: Phenylethylbi-guanidide causes only partial inhibition even at relatively high concentrations. Decamethylenedi-guanidide inhibits about $70 \%$ of the malate respiration, $55 \%$ of the succinate respiration, and $35 \%$ of the ascorbate-tetramethyl-p-phenylenediamine respiration. Finally, octyl-guanidine hydrochloride inhibits all three phosphorylation sites and the cyanide-insensitive respiration, but to differing extents and at different concentrations (Wilson and Bonner 1970).

This work aimed at studying the effect of sodium azide and guanidine hydrochloride as examples of two chemical mutagens on the in vitro growth of Gardenia jasminoides. Also, it aimed to produce genetic variation in the morphological and chlorophyll content. RAPD-PCR is used as a molecular marker to detect variations.

\section{Materials and Methods}

Gardenia jasminoides (Ellis) plants were collected from the gardens of the Faculty of Agriculture. Two different mutagens used were sodium azide and guanidine hydrochloride. The nodal explants were sterilized and cultured on MS. Then the plantlets were regenerated twice on $3 / 4$ MS growth regulator-free media for multiplication. The plantlets were cut into nodal explants and immersed in different concentrations of mutagens for $3 \mathrm{hrs}$. The explants were then washed in sterile distilled water, transferred to new MS jars, and incubated for 5 weeks in $16 \mathrm{hrs} \mathrm{light} / 8$ hrs dark incubators at $25^{\circ} \mathrm{C}$.

Eight selected morphological parameters such as fresh weight, shoot length, roots length, number of lateral roots, number of leaves, numbers of branches, leaf length, and leaf width.were used to compare the mutants with the control plants. 
Chlorophylls were estimated for both mutants and the control plants. Chlorophyll a, $\mathrm{b}$ and carotenoids were determined in the fresh leaves of the plantlets, according to Metzner et al. (1965). Fresh leaves of known weight were homogenized in $85 \%$ acetone. After centrifugation the supernatant containing the pigments was made up to a definite volume with $85 \%$ acetone. The extract was measured against a blank of pure $85 \%$ aqueous acetone at three wavelengths of 452,645 and $664 \mathrm{~nm}$ using a colorimeter. The concentration of chlorophyll a, b and carotenoids were calculated as $\mu \mathrm{g} / \mathrm{ml}$ using the following equations:

$$
\begin{aligned}
& \text { Chlorophyll } \mathrm{a}=10.3 \text { E664 - 0.918 E645 } \\
& \text { Chlorophyll } \mathrm{b}=19.7 \text { E645 }-3.87 \text { E664 } \\
& \text { Carotenoids }=4.3 \text { E452 (0. } 0265 \text { Chl } \mathrm{a}+0.426 \text { Chl. } \mathrm{b})
\end{aligned}
$$

Then, the fractions were calculated as $\mathrm{mg} / \mathrm{g}$ fresh weight:

$$
\frac{\text { Fraction } \times \text { dilution }}{1000} \mathrm{mg} / \mathrm{g}
$$

The total genomic DNA of G. jasminoides (different treatments) was isolated using CTAB method, according to Doyle and Doyle (1990) and modified by Edwards et al. (1991). A $0.5 \mathrm{~g}$ of leaves were ground with $700 \mu \mathrm{l}$ of $2 \%$ CTAB buffer and incubated at $65^{\circ} \mathrm{C}$ for $30 \mathrm{~min}$ with vortex every $10 \mathrm{~min}$. The Eppendorf tubes were centrifuged at $12,000 \mathrm{rpm}$ for $10 \mathrm{~min}$ and the supernatant was transferred into new tubes. Equal volume of chloroform: isoamyl alcohol mixture (24:1) and the supernatant was added to each other and set for $2 \mathrm{~min}$ at room temperature then centrifuged at 12,000 rpm for $10 \mathrm{~min}$ at $4^{\circ} \mathrm{C}$. The upper aqueous layer was transferred into new tubes and $800 \mu 1$ of absolute icecold ethanol was added and left for about $2 \mathrm{hrs}$ at $-20^{\circ} \mathrm{C}$, then centrifuged to precipitate DNA pellets and then washed with $70 \%$ ice-cold ethanol. Finally, the pellets were resuspended in $50 \mu \mathrm{l}$ of TE buffer and kept at $-20^{\circ} \mathrm{C}$ until the RAPD-PCR reaction was applied.

Seven RAPD decamer primers were used in this bioassay. Only 6 of them gave reproducible clear bands (Table 1). These primers were listed in Table 3. RAPD-PCR reaction was carried out in Biometra thermocycler. The reaction mixture was carried out in a total volume of $25 \mu \mathrm{l}$ containing $12.5 \mu \mathrm{l}$ Taq master mix (COSMO PCR RED M. Mix,

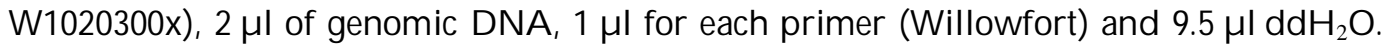
The reaction program was 35 cycles of the following steps: Denaturation for $30 \mathrm{sec}$ at $94^{\circ} \mathrm{C}$, annealing $30 \mathrm{sec}$ at different degrees for each primer as shown in Table 3 and extension for $1 \mathrm{~min}$ at $72^{\circ} \mathrm{C}$. This was followed by one step of the final extension at $72^{\circ} \mathrm{C}$ for $10 \mathrm{~min}$ then cooling at $4^{\circ} \mathrm{C}$. The amplified PCR product was run on $1.2 \%$ agarose gel compared to (New England Biolab, \#N3232S) ladder.

The gel electrophoresis images were analyzed using Bio-Rad Quantity one (4.6.2) software. The presence of a band was scored as 1, whereas the band's absence was coded 
as 0. A pairwise similarity matrix was generated using Jaccard's similarity coefficient. Using the unweighted pair group method with the arithmetic averaging algorithm (UPGMA), cluster analysis was performed to develop a dendrogram (Shuaib et al. 2007).

Table 1. List of primers, their nucleotide sequences used in the RAPD analysis of Gardenia jasminoides.

\begin{tabular}{lllll}
\hline No. & Primer & Sequence & GC $\%$ & Tm \\
\hline 1 & OPA-03 & 5'-AGTCAGCCAC-3' & 60 & 32 \\
2 & OPA-04 & 5'-AATCGGGCTG-3' & 70 & 34 \\
3 & OPB-17 & 5'-AGGGAACGAG-3' & 60 & 33.1 \\
4 & OPB-18 & 5'-CCACAGCAGT-3' & 60 & 32.6 \\
5 & OPD-07 & 5'-TTGGCACGGG-3' & 70 & 34.8 \\
6 & OPM-07 & 5'-CCGTGACTCA-3' & 60 & 33.2 \\
\hline
\end{tabular}

Data collected were subjected to analysis of variance test in SPSS 21. Mean average, standard deviations and correlations were estimated. Significant means were separated using Tukey test multivariate analysis. Tukey homogeneous subsets were applied for the different 25 treatments using one-way ANOVA for the two factors using multivariate analysis.

\section{Results and Discussion}

The variations in morphological parameters are shown in Fig. 1 and Table 2) for Gardenia jasminoides. There were significant differences due to the applications of treatments. Sodium azide stimulated a number of branches, number of leaves and leaf length significantly as against guanidine hydrochloride, which caused stimulation in all growth and morphological parameters except root length.

For photosynthetic pigmentation of G. jasminoides, chlorophyll content was estimated for the response of these plants to the different concentrations of mutagens (Table 3). It was noticed that chlorophyll a, b and carotenoids are inhibited using both the mutagens. All the mutant's pigmentation decreased significantly compared to control individuals. The $\mathrm{p}$ value of these morphological parameters and chlorophyll pigmentations showed a significant difference in various mutagens concentrations.

Gardenia jasminoides being an ornamental and medicinal plant it can be mutated to enhance their decorative characters and increase their therapeutic value.

Malaysian Nuclear Agency (Nuclear Malaysia) has started research on improvement of ornamental plants' through induced mutations. Nuclear Malaysia has produced more than 20 new varieties of ornamental and landscaping plants. These new varieties have been transferred to various end-users, private nurseries and government agencies 
(Ahmad et al. 2012). Sodium azide was used in many studies to induce mutation, as found by El-Nashar (2006) on Amaranthus caudatus, Al-Gawwad and Makka (2009) on Mirabilis jalapa and Mostafa (2011) on Helianthus annuus. Al-Qurainy (2009) used sodium azide mutagen with Eruca sativa and an estimated 9 morphological parameters and photosynthetic pigments. He proved that sodium azide causes significant differences. Also, El-Nashar and Asrar (2016) used chemical mutagens to assess the variation in Calendula officinalis as ornamental and medicinal plants. They estimated many morphological and physiological parameters and found significant differences in mutants compared to control.
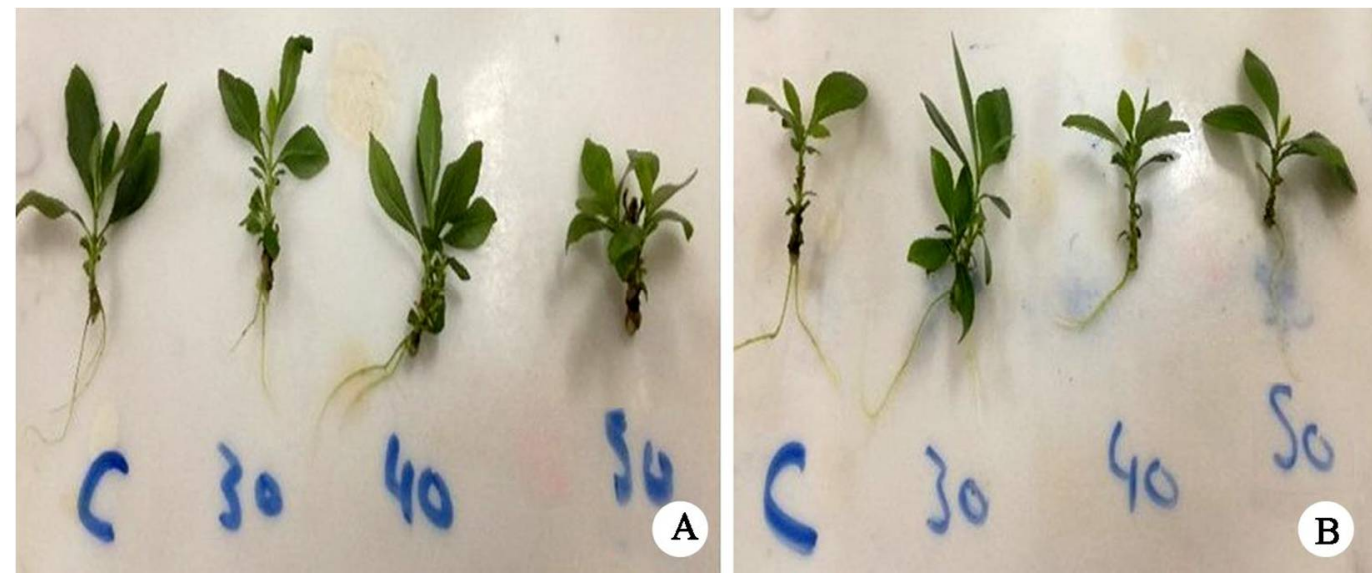

Fig. 1. Morphology of Gardenia jasminoides in response to different concentrations of mutagens.

A. Effect of sodium azide and B. Effect of guanidine hydrochloride.

For molecular marker analysis, the total genomic DNA was extracted and RAPDPCR was performed to estimate the genetic variation resulted from mutagen treatments. The results of selected oligonucleotides decamers were visualized on an agarose gel (Fig. $2 \mathrm{a}, \mathrm{b})$ for sodium azide and guanidine hydrochloride, respectively. The polymorphism data resulted from these primers are illustrated in the Table (4). The total polymorphism percentage of G. jasminoides affected by sodium azide was 57.71 as against 67.59 in guanidine hydrochloride treatment. Tables 5 and 6 showed the similarity matrix of the different concentrations of sodium azide and guanidine hydrochloride, respectively. The dendrogram showed the genetic effect of sodium azide on G. jasminoides (Fig. 3). It illustrated that control and $30 \mathrm{mM}$ treatment were closely related to each other, where 40 and $50 \mathrm{mM}$ treatments were related. The genetic effect of guanidine hydrochloride is shown in Fig. 4. It illustrated that $50 \mathrm{mM}$ is separated away, where 30 and $40 \mathrm{mM}$ are genetically similar and quite related to control. 
Table 2. Morphological means estimation of Gardenia jasminoides in response to different concentrations of mutagens.

\begin{tabular}{|c|c|c|c|c|c|c|c|c|}
\hline \multirow{2}{*}{$\begin{array}{l}\text { Mutagen } \\
\text { Conc. (mM) }\end{array}$} & \multicolumn{4}{|c|}{ Sodium azide } & \multicolumn{4}{|c|}{ Guanidine hydrochloride } \\
\hline & 0 & 30 & 40 & 50 & 0 & 30 & 40 & 50 \\
\hline Fresh wt. (g) & 0.1134 & 0.1546 & 0.1600 & 0.1268 & 0.1277 & 0.1174 & 0.1448 & 0.1089 \\
\hline Shoot length $(\mathrm{cm})$ & 1.4750 & 1.9500 & 1.8000 & 1.2750 & 1.5333 & 1.6000 & 2.1000 & 1.7500 \\
\hline Root length (cm) & 3.2500 & 2.3000 & 2.3250 & 1.5500 & 3.3667 & 3.0333 & 2.3000 & 2.8667 \\
\hline No. of roots & 3.0000 & 1.3333 & 2.3333 & 1.3333 & 2.5000 & 2.5000 & 1.2500 & 1.0000 \\
\hline No. of leaves & 6.0000 & 7.6667 & 6.6667 & 7.3333 & 6.0000 & 4.6667 & 7.6667 & 5.6667 \\
\hline No. of branches & 1.0000 & 1.6667 & 1.3333 & 1.6667 & 1.0000 & 1.6667 & 1.0000 & 1.0000 \\
\hline Leaf length $(\mathrm{cm})$ & 1.8750 & 2.1833 & 1.9417 & 1.7667 & 1.8214 & 1.9357 & 2.6071 & 2.4000 \\
\hline Leaf width (cm) & 0.9000 & 0.9083 & 0.7917 & 0.8083 & 0.8571 & 0.9357 & 1.1571 & 0.8643 \\
\hline $\mathrm{p}$ value & 0.000 & 0.000 & 0.000 & 0.000 & 0.000 & 0.000 & 0.000 & 0.000 \\
\hline $\mathrm{F}$ value & 11.374 & 41.894 & 44.527 & 23.532 & 9.606 & 5.825 & 23.837 & 55.326 \\
\hline
\end{tabular}

Table 3. Chlorophyll content of Gardenia jasminoides in response to different concentrations of mutagens.

\begin{tabular}{|c|c|c|c|c|c|c|c|c|}
\hline \multirow{2}{*}{$\begin{array}{l}\text { Mutagen } \\
\text { Conc. (mM) }\end{array}$} & \multicolumn{4}{|c|}{ Sodium azide } & \multicolumn{4}{|c|}{ Guanidine hydrochloride } \\
\hline & 0 & 30 & 40 & 50 & 0 & 30 & 40 & 50 \\
\hline Chl. a & 0.920519 & 0.617812 & 0.706645 & 0.709272 & 0.91927 & 0.48513 & 0.52971 & 0.54479 \\
\hline Chl. b & 0.807074 & 0.617927 & 0.524632 & 0.509406 & 0.80674 & 0.37548 & 0.42432 & 0.43233 \\
\hline Cart. & 0.531713 & 0.391106 & 0.345430 & 0.315179 & 0.53131 & 0.24691 & 0.28064 & 0.27576 \\
\hline $\mathrm{p}$ value & 0.000 & 0.000 & 0.000 & 0.000 & 0.000 & 0.000 & 0.000 & 0.000 \\
\hline F value & 14427.43 & 15382.69 & 13312.98 & 4964.66 & 24012.76 & 23474.59 & 35459.79 & 9554.068 \\
\hline
\end{tabular}

Many molecular markers were used to assess the genetic variation in plants in response to mutation. In this study, RAPD-PCR was the molecular marker used to detect the genetic polymorphism within G. jasminoides due to the action of both sodium azide and guanidine hydrochloride. Li et al. (2009) performed a study to evaluate the genetic differences and mutual relationship of G. jasminoides at DNA level among different cultivars using ISSR molecular marker and obtained a polymorphism percentage of $55.17 \%$. Wannajindaporn et al. (2014) used tissue culture technique to study the effect of sodium azide on Dendrobium ornamental plant and used ISSR molecular markers to estimate the variation in mutants compared to control. This agrees with many workers which proved the genetic variation in different plants due to chemical mutagens treatments. Kishk et al. (2016) used ISSR molecular marker to estimate both diethyl sulphate and sodium azide mutagen on banana plant to against salt stress. 

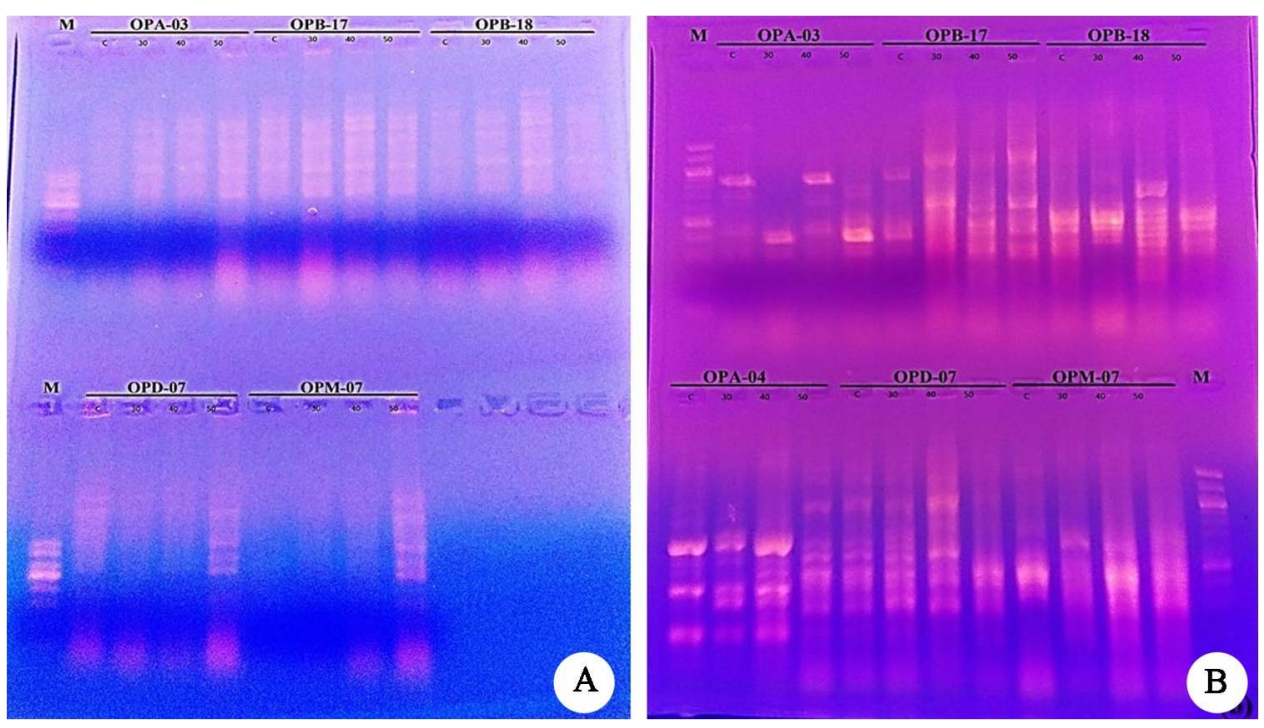

Fig. 2. Agarose gel electrophoresis of Gardenia with mutagen. A. Sodium azide and B. Guanidine hydrochloride.

Table 4. List of primers, their nucleotide sequences and polymorphism percentage used in the RAPD analysis of Gardenia jasminoides with both mutagens.

\begin{tabular}{lcccccc}
\hline & & \multicolumn{2}{c}{ Sodium azide } & & \multicolumn{2}{c}{ Guanidine hydrochloride } \\
\cline { 3 - 4 } \cline { 6 - 7 } No. & Primers & $\begin{array}{r}\text { Total } \\
\text { bands }\end{array}$ & $\begin{array}{c}\text { Polymorphism } \\
(\%)\end{array}$ & & $\begin{array}{c}\text { Total } \\
\text { bands }\end{array}$ & $\begin{array}{c}\text { Polymorphism } \\
(\%)\end{array}$ \\
\hline 1 & OPA-03 & 5 & 60 & & 7 & 71.42 \\
2 & OPA-04 & - & - & & 12 & 41.67 \\
3 & OPB-17 & 7 & 42.85 & & 8 & 100 \\
4 & OPB-18 & 8 & 25 & & 6 & 50 \\
5 & OPD-07 & 4 & 75 & & 10 & 80 \\
6 & OPM-07 & 7 & 85.71 & & 8 & 62.5 \\
Total & & & & 57.71 & & 67.59 \\
\hline
\end{tabular}

Table 5. Similarity matrix resulted from all RAPD primers for Gardenia treated with sodium azide

\begin{tabular}{lllll}
\hline & Control & $30 \mathrm{mM}$ & $40 \mathrm{mM}$ & $50 \mathrm{mM}$ \\
\hline Control & 100 & 68.70 & 56.26 & 55.96 \\
$30 \mathrm{mM}$ & 68.70 & 100 & 61.98 & 55.00 \\
$40 \mathrm{mM}$ & 56.26 & 61.98 & 100 & 71.84 \\
$50 \mathrm{mM}$ & 55.96 & 55.00 & 71.84 & 100 \\
\hline
\end{tabular}




$\longdiv { 4 . 3 1 \mathrm { E } 3 } \quad 1 . 9 9 \mathrm { E }: 1.63 \mathrm{E} 3 \quad 0$

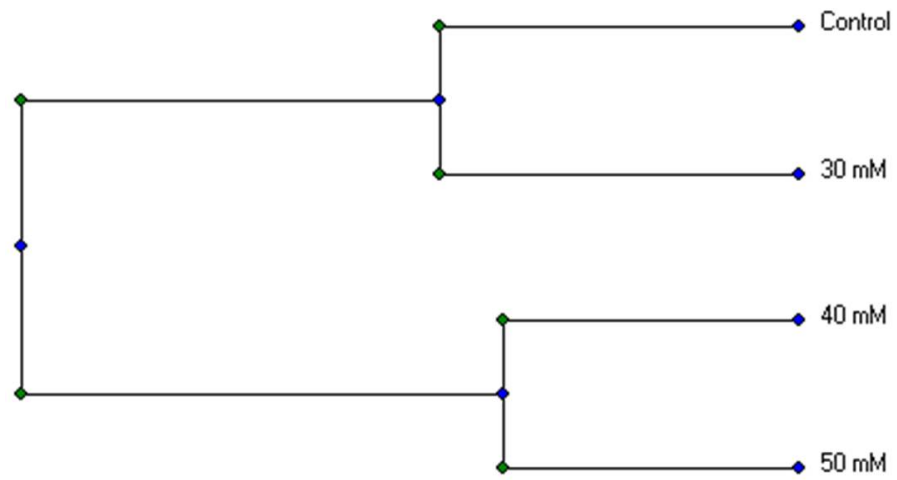

Fig. 3. Dendrogram resulted from all RAPD primers for Gardenia treated with sodium azide.

Table 6. Similarity matrix resulted from all RAPD primers for Gardenia treated with guanidine hydrochloride.

\begin{tabular}{lcccc}
\hline & Control & $30 \mathrm{mM}$ & $40 \mathrm{mM}$ & $50 \mathrm{mM}$ \\
\hline Control & 100 & 52.63 & 57.25 & 38.07 \\
$30 \mathrm{mM}$ & 52.63 & 100 & 59.67 & 41.70 \\
$40 \mathrm{mM}$ & 57.25 & 59.67 & 100 & 48.48 \\
$50 \mathrm{mM}$ & 38.07 & 41.70 & 48.48 & 100 \\
\hline
\end{tabular}

\begin{tabular}{llll}
\hline $7.87 E 3$ & $4.51 E 3$ & $3.32 E 3$ & 0
\end{tabular}

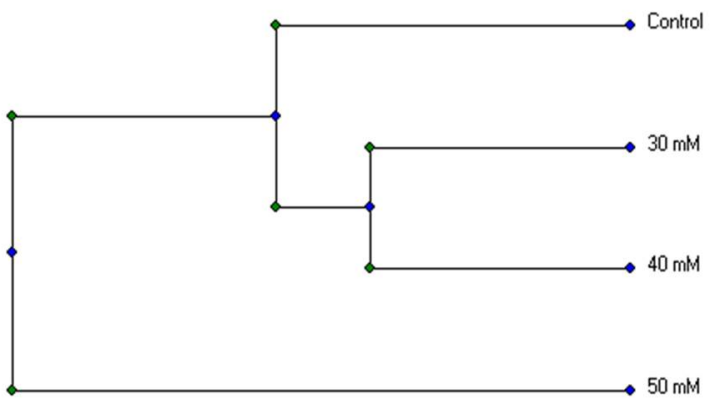

Fig. 4. Dendrogram resulted from all RAPD primers for Gardenia treated with guanidine hydrochloride. 


\section{Acknowledgment}

The authors would like to thank the Agricultural Center for Genetic Engineering and Biotechnology ACGEB, Faculty of Agriculture, Ain Shams University, for the facilitiesof working in tissue culture laboratory

\section{References}

Ahmad Z, Hassan AB, Salleh S, Ariffin SN, Shamsudin S, Basiran MN, Tan SG, Zainudin NA and Yusoh OM (2012) Improvement of Malaysian ornamental plants through induced mutation. Pertanika J. Trop. Agric. 35(3): 631-636.

Al Gawwad A and Makka AH (2009) Effect of chemical mutagens on Mirabilis jalapa. M.Sc. Thesis, Floriculture, Faculty of Agriculture, Alexandria University, Alexandria, Egypt.

Al-Qurainy F (2009) Effects of sodium azide on growth and yield traits of Eruca sativa (L.). World Appl. Sci. J. 7(2): 220-226.

Doyle JJ and Doyle JL (1990) Isolation of plant DNA from fresh tissue. Focus 12: 13-15.

Edwards K, Johnstone C and Thompson C (1991) A simple and rapid method for the preparation of plant genomic DNA for PCR analysis. Nucleic Acid Res. 19: 349. doi: 10.1093/nar/19.6.1349

El-Mokadem HE and Mostafa GG (2014) Induction of mutations in Browallia speciosa using sodium azide and identification of the genetic variation by peroxidase isozyme. Afr. J. Biotechnol. 13(1): 106-111.

El-Nashar YIA (2006) Effect of chemical mutagens (sodium azide and diethyl sulphate) on growth, flowering and induced variability in Amaranthus caudatus L. and A. hypochondriacus L. Ph.D. Thesis, Floriculture, Faculty of Agriculture, Alexandria University, Alexandria, Egypt.

El-Nashar YI and Asrar AA (2016) Phenotypic and biochemical profile changes in calendula (Calendula officinalis L.) plants treated with two chemical mutagenesis. Genet. Mol. Res. 15(2): gmr.15028071.

Kesavan K, Gnanasekaran J, Gurunagarajan S and Nayagam AAJ (2018) Microscopic, physicochemical and phytochemical analysis of Gardenia jasminoides (Ellis). Int. J. Pharm. Pharm. Sci. 10(1): 97-102.

Kishk AD, Abul-Soad AA, Abbas MS, El-Shabrawi HM, Gaber EI and Noor El-Deen TM (2016) Effect of diethyl sulphate and sodium azide on tolerance of ex vitro banana to salt stress. International Journal of Chem. Tech. Res. 9(12): 81-99.

Li L, Yi W, A-Man Z, Pei-Lin Z and Shi-Liang Z (2009) Genetic relationship of Gardenia jasminoides among plantations revealed by ISSR. Chin. Tradit. Herbal Drugs 40(1): 116-120.

Metzner H, Rau H and Senger H (1965) Untersuchungenzur synchronisie-rbarkeiteinzelner pigmentmangel mutanten von chlorella. Planta 65: 186-194.

Mostafa GG (2011) Effect of sodium azide on the growth and variability induction in Helianthus annuus L. Int. J. Plant Breed. Genet. 5(1): 76-85.

Shuaib M, Zeb A, Ali Z, Ali W, Ahmad T and Khan I (2007) Characterization of wheat varieties by seed storage protein electrophoresis. African J. Biotech. 6: 497-500.

Soliman TMA, El-Keltawi NE, Khan MA, Nan M and Zhao LJ (2013) plant growth and flowering of cape jasmine (Gardenia Jasminoides, Ellis) in various substrates amended with sulphur. Glob. J. Plant Ecophysiol. 3(2): 36-43. 
Suprasanna P, Mirajkar SJ and Bhagwat SG (2015) Induced mutations and crop improvement. Plant Biotechnol. 1: 593-617.

Wannajindaporn A, Poolsawat O, Chaowiset W and Tantasawat PA (2014) Evaluation of genetic variability in in vitro sodium azide-induced Dendrobium 'Earsakul' mutants. Genet. Mol. Res. 13(3): 5333-5342.

Wilson SB and Bonner WD (1970) Effects of guanidine inhibitors on mung bean mitochondria. Plant Physiol. 46: 21-24.

Xiao W, Li S, Wang S and Ho CT (2017) Chemistry and bioactivity of Gardenia jasminoides. Review Article. J Food Drug Anal. 25: 43-61.

(Manuscript reeived on 16 August, 2020; revised on 21 September, 2020) 